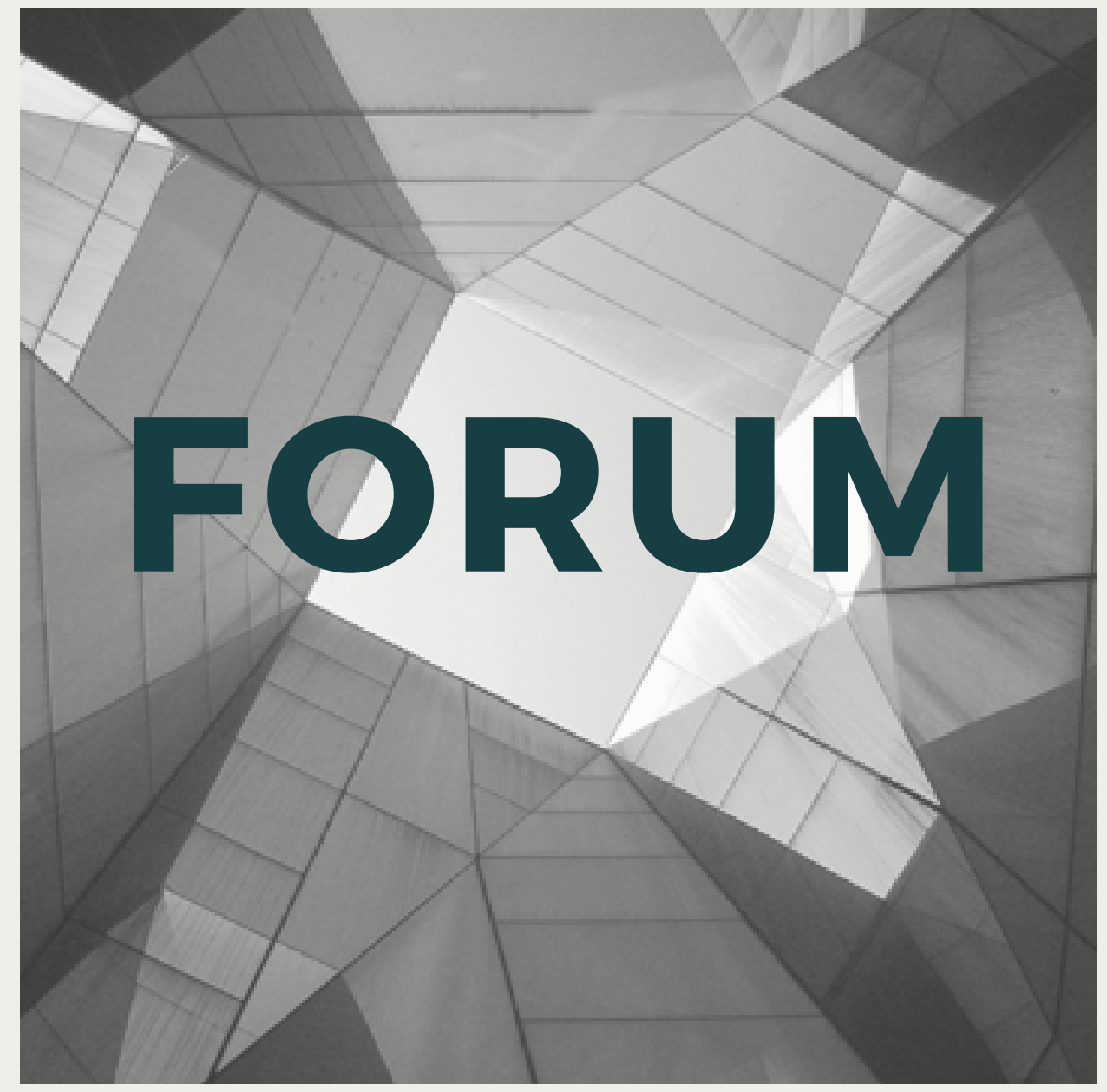

\title{
Interpreting the Rule of Law in China
}

Edited by Elisa Nesossi

With the participation of

Joshua Rosenzweig

Ewan Smith

Susan Trevaskes 

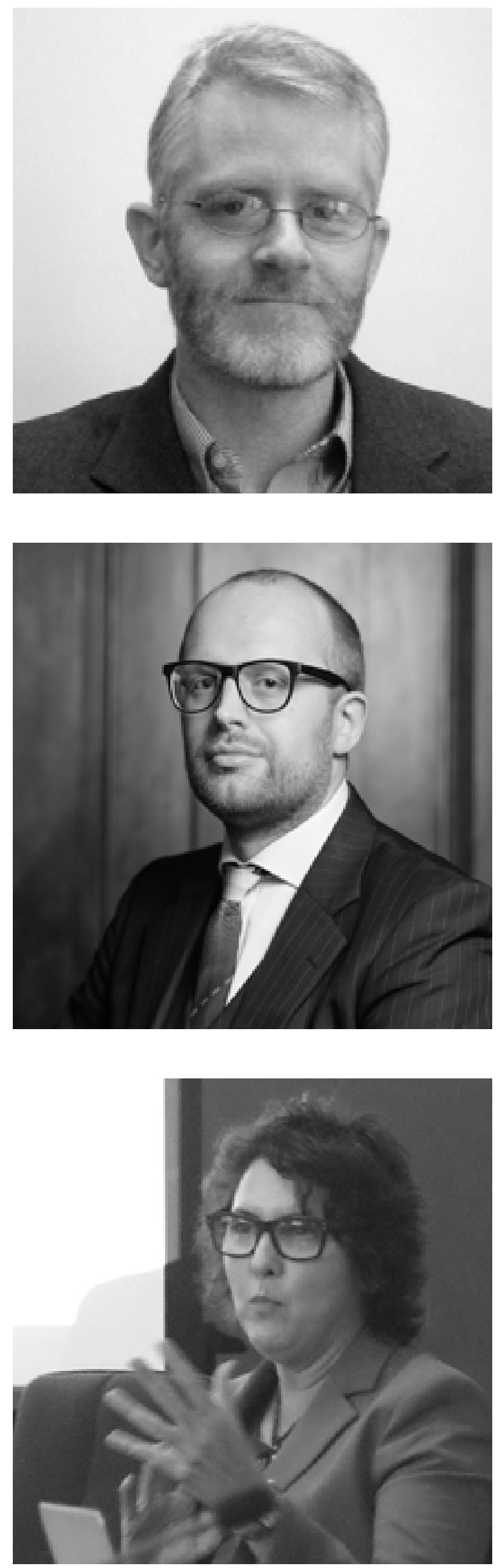

\section{Joshua Rosenzweig}

Joshua is a Business and Human Rights Strategy Advisor/Analyst at Amnesty International's East Asia Regional Office in Hong Kong, where he has lived since 2008. An observer of all things Chinese for more than 25 years, he has more than a decade of experience researching, analyzing, and teaching about human rights developments and criminal justice in China. His current work focuses on the human rights impacts of Chinese business operations overseas and promoting responsible business conduct and corporate accountability. The views expressed in this piece are his own and do not necessarily represent the views of Amnesty International.

\section{Ewan Smith}

Ewan is a Lecturer at Trinity College (Oxford). He is admitted to practice in New York, where he worked for Debevoise and Plimpton. In 2005, he joined the Foreign and Commonwealth Office and worked on UK policy towards the Middle East and China. From 2009-2014 he was posted to Beijing, where he analysed developments in Chinese leadership politics and government policy, with a particular focus on the reform of the legal system and the fight against corruption.

\section{Susan Trevaskes}

Susan is a professor of the Griffith Criminology Institute at Griffith University (Australia) and an Adjunct Director of the Centre on China in the World at the Australian National University. Her main research interests include the death penalty, policing, drug crime, public shaming events, and justice system reform in China. 


\title{
Interpreting the Rule of Law in China
}

\author{
Edited by Elisa Nesossi,
}

with the participation of Joshua Rosenzweig, Ewan Smith, Susan Trevaskes
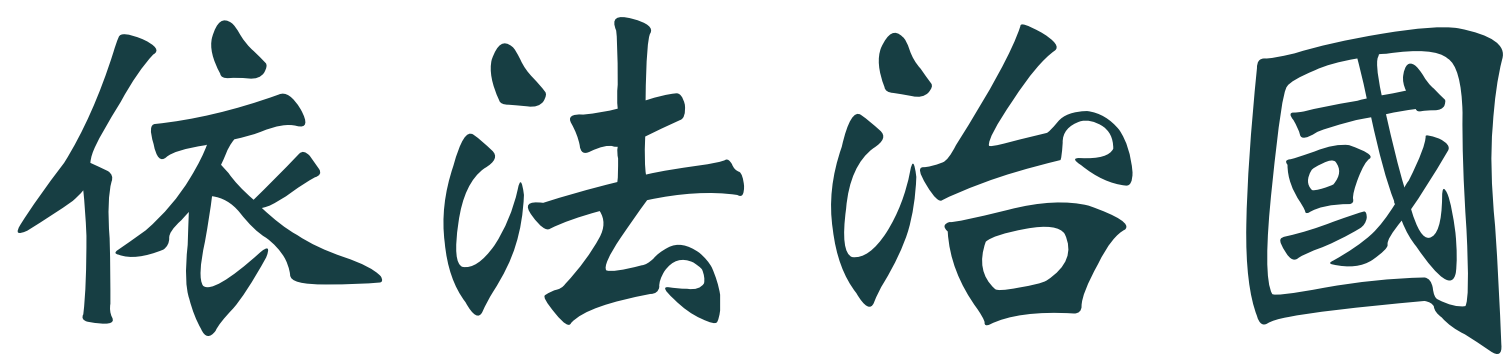

'Yifa zhiguo', the Chinese expression often translated as 'rule of law'

With its ample resonance both within China and internationally, the 'rule of law' (yifa zhiguo) is an expression that can justify the most disparate justice reforms. It is both a political value worth defending and a reason for consternation; it is an ideal that is inherently troubling and troubled by its interlocutors, advocates, and critics. For this reason, even the term 'yifa zhiguo' has been translated differently by different interlocutors, with 'rule of law', 'rule by law' and 'ruling the country according to the law' being the most frequent renderings in the English language.

While the rule of law has become a key component of the Chinese legal-political vocabulary since the onset of the reform period, under Xi Jinping's leadership it appears to have increased in importance. Since Xi Jinping took the helm in 2012, he has chosen to adopt exactly this expression to shape his policy and justice agendas. But the authoritarian way in which the concept has been used thus far has, in many quarters, produced a palpable sense of surprise and dismay over the future of the Chinese legal system. The current leadership is shaping. what at first glance seems to be quite incongruous goals-fighting corruption and the erosion of institutional credibility; fighting criminals and dissenters who threaten stability; and guarding against national and international security threats-all under the same rhetorical and ideological rubric. During the last year, the rule of law has served the practical function of maintaining social stability and controlling dissent. It has equally justified anti-corruption campaigns targeting party officials, and the repression of civil society and human rights activism. Although their activities remained well within the legal or constitutional rights of Chinese citizens, lawyers, labour activists, and people working for NGOs became key targets of repression, with hundreds of arrests of lawyers in the summer of 2015 alone.

Through a discussion between three experts on the historical and ideological development of socio-legal issues in China-Joshua Rosenzweig, Ewan Smith and Susan Trevaskes-this Forum aims at reframing our understanding of Xi's 'rule of law' agenda and enriching our sense of the meaning of this contested expression in the contemporary political context. 
The expression 'yifa zhiguo' may be translated in different ways. The most common renderings in English are 'rule of law', 'rule by law', 'ruling the country according to the law'; however, each of these translations carries different connotations. How would you best translate 'yifa zhiguo' and, in your view, what is the meaning of this expression in contemporary China?

Joshua Rosenzweig: I think that part of the reason why this expression has so many different translations is that the meaning can be very context-dependent. As with other ideologically significant phrases, there are hegemonic uses that serve to reinforce existing power structures and there are counter-hegemonic uses that work against those structuresoften deliberately, sometimes less so. Most people probably have a particular understanding of what they mean when they use the phrase at any given point, but once those usages become part of the public discourse, they can be understood in ways that were not necessarily intended. Put simply, I think that the differences boil down to whether or not one believes that law has any autonomous moral authority of its own, separate from political power. When Chinese officials speak of 'yifa zhiguo', they are thinking of law purely in terms of a tool of governance. Law establishes rules that reflect the morality that is assumed to inhere in political order, and a society that understands and follows those rules is, therefore, a good and just society. I do not think it matters too much whether you call this notion 'rule by law' or 'rule according to law'. When others talk about 'yifa zhiguo'or its cousin 'fazhi'-it is clear that they are, in fact, thinking in terms of law as a source of authority that is distinguishable from power. As such, for them law reflects external standards that should set bounds for the behaviour of the regime, not just society. I think this is closer to what many people mean when they think of rule of law. Because the difference comes from different understandings of ' $f a$ ', so the same phrase can connote different things to different people.

Ewan Smith: Neither rule of law nor 'yifa zhiguo' has a fixed meaning: both expressions refer to a range of contested ideas. There is a partial overlap between the English and the Chinese phrases. Sometimes, 'yifa zhiguo' means something similar to rule of law. For example, if the words are used casually, to describe an alternative to arbitrary government, the 'rule of law' is the best translation because it is familiar. In contrast, 'rule by law' and 'ruling the country according to the law' are unfamiliar expressions that jar the reader. They draw attention to the fact that 'yifa zhiguo' means something different, unfamiliar and even dissonant to rule of law. In some contexts, it is important to underline these differences by translating 'yifa zhiguo' in this way. It would be unwise to offer an all-purpose definition of 'yifa zhiguo', just as it would be unwise to give an all purpose definition of the rule of law. It might mean the same thing A.V. Dicey, or Lon Fuller, or Tom Bingham meant when they said 'rule of law'. But in official discourse, this is unlikely.

Susan Trevaskes: 'Yifa zhiguo' is probably best translated as 'Governing the Nation [or country] in accordance with the law.' This is a concept that developed in the mid-1990s drawing on basic ideas about socialist rule of law from the 1980s. It began in the 1990s as a slogan that stood for greater emphasis on the use of law and regulations in state administration. It does not mean a separation of the Party from the state. To the contrary, governance in China since the 1990s has seen the embedding of the Party within the state through party groups (xiaozu) planted in all areas of government which comprise members holding key positions (such as a governor of a province). The Party delegates authority to state institu- 
tions for routine governance while continuing to lead exclusively over political, ideological and institutional matters.

In your opinion, to what extent has the use of the concept 'yifa zhiguo' changed in Xi Jinping's China in comparison to the Jiang Zemin and Hu Jintao eras? Can you please highlight both continuities and changes?

JR: I do not think that Jiang Zemin or $\mathrm{Hu}$ Jintao had substantially different understandings of the concept of ' $y$ ifa zhiguo' compared to Xi Jinping. But Xi Jinping seems to have given the idea a bit of a renaissance and made it a more prominent part of his agenda. One reason is that Xi Jinping sees rule-based governance as a way to impose discipline and centralise control over the party-state bureaucracy. The stress of the previous decades had been on promoting economic growth and maintaining social stability, and there was a tacit understanding that as long as these results were achieved there would not be too many questions from above about who was getting rich on the side or what methods were employed to maintain stability. But corruption, inequality and 'rigid stability' tactics contributed to a growing sense of popular injustice that needed to be addressed in some way. Moreover, given the daunting task of reorienting China's economy, the country's leaders need to be able to count on the bureaucracy to respond to its directions instead of playing by its own rules. Another reason for the prominence of 'yifa zhiguo' under Xi Jinping is that China's current leadership is trying to restore the party-state's ideological dominance by flooding the public discourse with its own messages and squeezing out any alternative usages. The promotion of 'yifa zhiguo' in the 1990s coincided with the re-emergence of a relatively autonomous arena for discussion and debate of public affairs in which matters of law and justice formed an important part. For a while, ideas about human rights, procedural justice and constitutionalism flourished and shaped critical notions of how law might function in China. Recognising the challenge posed by these alternative ideas, Xi Jinping has taken steps to iso-

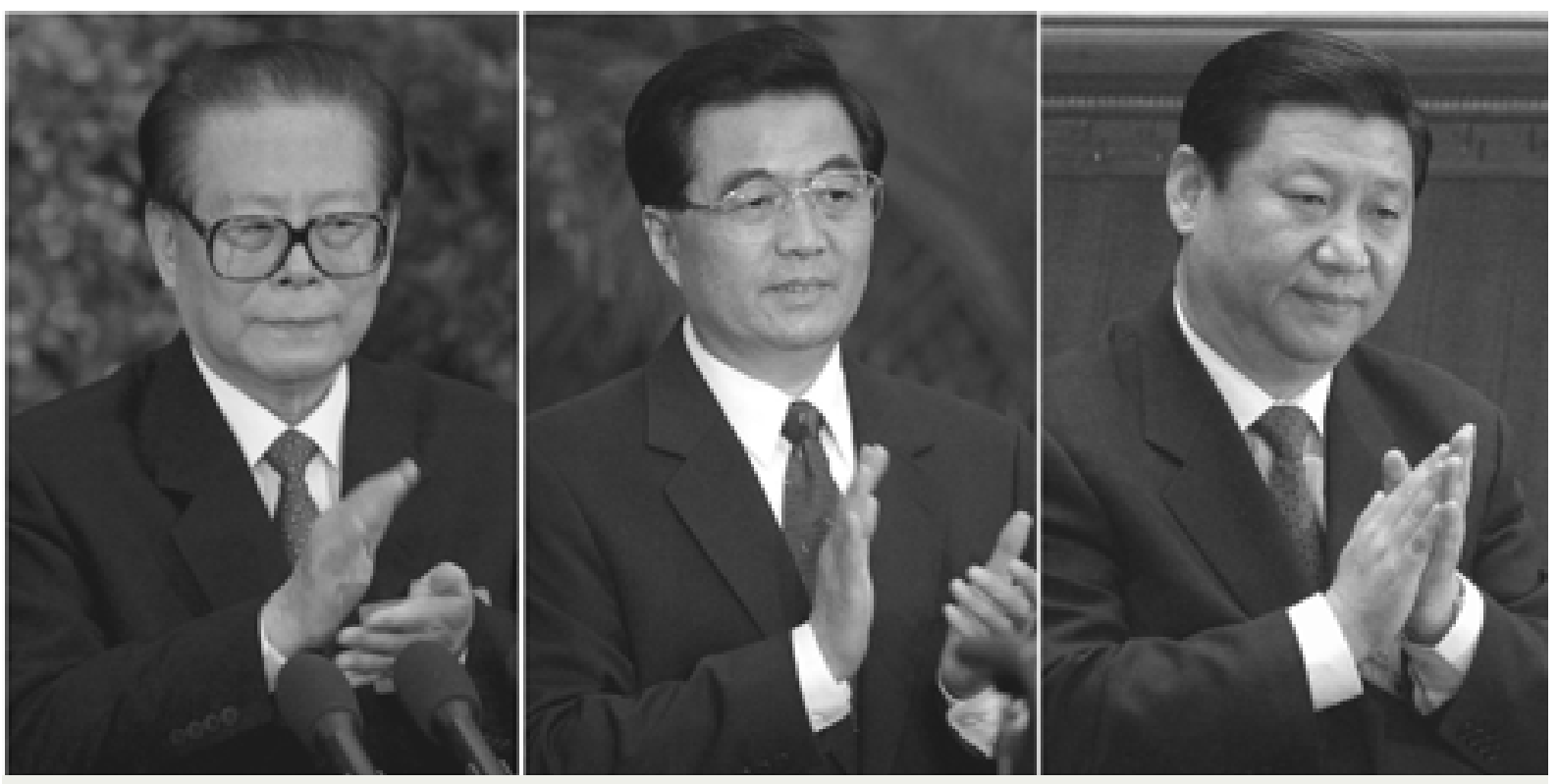

Jiang Zemin, Hu Jintao and Xi Jinping have guided the Chinese Communist Party for almost three decades. PC: South China Morning Post 
late and excise these views from the public discourse and 'unify thinking' around orthodox views of law and justice.

ES: Hu Jintao came to power less than a year after China acceded to the WTO. During Hu's administration, the 'yifa zhiguo' policy was often presented as necessary step towards compliance with rule of law obligations, and as an instrument to achieve bigger economic objectives, such as the 'xiaokang shehui' or 'moderately prosperous society'. Over time, we see more and more language presenting the rule of law as something that is instrumentally good. In the official discourse, rule of law became an 'essential guarantee' of policy goals as diverse as 'socialist material, spiritual and political culture', the 'three represents' and 'scientific development'. In his explanation of the Decision of the Fourth Plenum from 2014, $\mathrm{Xi}$ mirrors this language. He describes the rule of law as a 'fundamental requirement' for 'safeguarding social harmony and stability', 'guaranteeing the longterm peace and order of the Party and the country' and '[promoting] the sustained and healthy development of our country's economy and society'. But one important change under Xi has been a decidedly voluntarist turn in the use of the rule of law, especially with the advent of the current anti-corruption campaign. Under $\mathrm{Xi}$, the rule of law has been partially subordinated to an agenda that seeks to contain power 'within the cage of regulation' (ba quanli guanjin zhidu de longzi li). It is not a tool that can rectify institutions. Instead, it is one of a series of tools that can rectify individuals.

ST: The use of 'yifa zhiguo' in the $\mathrm{Xi}$ Jinping, Hu Jintao and Jiang Zemin eras is essentially the same, but $\mathrm{Xi}$ has given it a new twist, emphasising the idea of Party leadership through the rule of law. The Resolution of the historic Fourth Plenum of the $18^{\text {th }}$ Party Congress in 2014 states that the Party's leadership [over and through government] and socialist rule of law are identical. Crucially, the document insists that the Party will now 'implement its leadership role through the rule of law'. The meaning of 'yifa zhiguo', or at least the purpose to which it is has been put to use by Xi Jinping and close colleagues, is to accentuate a particular relationship between the party-state and the people. After a decade of Hu Jintao's 'Harmonious Society' and 'Stability Maintenance' in the 2000s, it had become apparent to the incoming Xi Party leadership that rigid Stability Maintenance operations were severely undermining judicial and political credibility, and could not be sustained as a long-term political solution. To win back the hearts and minds of people whose trust in the law had been seriously eroded by party corruption, Xi Jinping and Li Keqiang began talking about accountability, transparency, clean government and so on. But this new platform required a substantial reinvigoration of centralised Party power in order to regain the capacity to limit corruption at the local level on the one hand, and to deal with perceived threats to national security on the other. Hence, we find Xi Jinping bringing Party supremacy back into political fashion. The ideological role of 'yifa zhiguo' in Xi's China, gives the Party rhetorical permission to govern China in such a way that it can deal with disunity, dissent and crime using the weapon of the law.

\section{How does history matter to the way in which 'yifa zhiguo' is officially in- tended today?}

JR: There are so many ways to approach this question, in part because there are different ways to think about 'history'. Let me focus on two. First, I would say that in contemporary China 'yifa zhiguo' has always been contrasted positively against the idea of the 'lawless' and arbitrary years under Mao, especially during the Cultural Revolution. The Maoist period 
is a useful benchmark for legal and institutional progress because, especially for the majority of people whose lives have improved since the 'reform and opening', there are so many reasons to be satisfied with the relative stability and security that China's current legal system has to offereven with its many flaws. But the utility of this referent is fading as time marches on, and there's reason to wonder whether Chinese citizens now in their 20s, 30s, and even $40 \mathrm{~s}$ will continue to evaluate the state of their legal system against the high point of legal nihilism under Mao. Second, I would say that history matters in the sense that, in the nearly 40 years since the beginning of the reform period, China has experienced historical changes that I would argue are transforming the way that Chinese people think about the state-centred justice model that underlies the official agenda of 'yifa zhiguo'. Several decades of socio-economic change have produced a society that is far more individualistic, diverse and contentious than the authoritarian stability-harmony model acknowledges. It is within such a society that alternative ideas about rights, checks on government, and procedural rights have started to make sense. China's current leaders seem to want to ignore the passage of time and the demands that socio-economic change has brought. They want to force society to conform to their vision of society, rather than adapt to the changed realities of that society. I do not think this is a sustainable strategy.

ES: History provides a reference point by which we can assess what it means to run the country according to law. While international comparison dominates the debate about the rule of law outside China, historical comparison is a much more important context for Chinese official discussion of 'yifa zhiguo'. Every politburo member grew up during the Cultural Revolution, and this serves as a framing device for 'yifa zhiguo'. Younger Chinese people grew up while a legal system was rebuilt from scratch around them. In the official discourse (especially the early official discourse) this sense of constant progress is offset against the type of arbitrary government that came before. In this way, history amplifies the importance of 'yifa zhiguo', it relativises it, and it emphasises the extent to which it has already been achieved. More broadly, for reasons that I touch on above, historical argument sets the tone and tempo for political reform in Chinese official discourse. During the seventeenth politburo, one reason why China needed to implement the rule of law policy was because 'prevailing historical conditions' meant the time was right. Likewise, at least in the official discourse, 'prevailing historical conditions' will dictate when China is ready for more democratic and accountable governance.

ST: The history of various discussions on socialist rule of law and a number of key political events in China have helped to shape 'yifa zhiguo' as we know it today. We can break up the term 'yifa zhiguo' into various parts - ' $f a$ ' then ' $y$ ifa' then 'yifa zhiguo' to understand the influence of history. First, in terms of law $(f a)$, from the early 1950s onwards, law in the PRC was seen as a manifestation of party policy. That is not to say that all laws were party policies, but that the intent of the law was basically in harmony with Party policy. After Deng Xiaoping came to power, the Party's ideas about the nature of law did not fundamentally change; law remained socialist in purpose and intent. As the scholar Harro von Senger noted in 1985, 'law does not serve the function of an autonomous force for shaping the social order, independent of the CCP Party norms. It serves rather as a vehicle for making casuistic elaborations to Party norms'. Second, the phrase 'yifa' (in accordance with the law) has its origins in the 1950s, particularly during a brief period after 1954 when the Constitution was promulgated. It was taken up again with gusto in the early 1980s as a 
phrase attached to various party-state actions such as 'severely punishing in accordance with the law (yifa yancheng) or '[Party] Rule in accordance with the law' (yifa zhizheng). Stressing ' $y$ ifa' in the 1980 s was an attempt to changed public and Party mindsets from 'rule of man' to 'rule of law'. This was a new consciousness of law based on the idea that law would institutionalised through courts and government agencies to create a basis for economic modernisation and a sound spiritual civilisation. Third in terms of 'yifa zhiguo' in the 1990s: It has been widely documented that the Party abandoned its aspiration of state-Party separation following the 1989 Tiananmen incident and the collapse of the Soviet Union. Therefore, progressively throughout the mid to late 1990 s, the relatively simple message about the benefits of rule-oflaw over rule-of-man was replaced with a more specific governance-based message about how the country should be ruled. This new political line required a new slogan, 'Governing the Nation in Accordance with the Law' (yifa zhiguo). 'Yifa zhiguo' became the platform under which the institutionalisation of the Party-state was to take place in China. It was a catchcry about how good governance should be achieved; through introduction of new laws and regulations aimed at better supervising and limiting administrative powers. In the late 1990s, 'yifa zhiguo' morphed into a political institutionalisation strategy, bolstering Party power to make concrete decisions about governance through Party groups and committees at all levels of government. President Jiang Zemin promulgated 'yifa zhiguo' at the $15^{\text {th }}$ Party Congress as the Party's ruling paradigm and it was inserted into the Constitution in 1999.

In your view, what is the relationship between 'yifa zhiguo' and 'yide zhiguo' (ruling the country according to virtue) in today's China?
JR: I think the ideas are meant to be complementary and acknowledge the two main strands of Chinese political tradition, Confucianism and Legalism. Even though these are often taken to be opposed, the reality is that for millennia Chinese leaders governed by mixing the two schools of thought. To me, the relationship between the two goes back to the assumption of a political regime that is inherently moral. The virtue of the regime's rulers is a manifestation of that morality but is also something that must be properly cultivated and reinforced. Law is necessary to guide virtuous behaviour among officials and society at large, but it too is intended as a manifestation of the moral regime. Both work together in a kind of balance that produces order and stability from the top down. I do not necessarily think this hearkening back to traditions of Chinese political-legal culture is part of any great ideological shift under $\mathrm{Xi}$, per se. These ways of thinking about power and the relationship between state and society are structural elements of Chinese culture that are being laid bare because the modern ideological garb that they have been wearing for over a century has begun to wear thin.

ST: To understand the significance of 'yide zhiguo' for 'yifa zhiguo' we need to understand the Confucian mindset of the Party. Party leaders assume a paternal fosterage role in enlightening a politically and legally illiterate citizenry. Xi has been continuously enlightening China's citizens of the necessity of a strong Party to rule in their interests

The concept of 'rule of law' very often seems to imply a teleological march from Marxism to a more liberal system of governance. In your view, to what extent will the 'yifa zhiguo' agenda be able to promote the development of a different, more democratic and accountable system of governance in China in the future? 
JR: In and of itself, the official legal development agenda associated with 'yifa zhiguo' is not intended to lead to liberal democracy for China, and I think the sooner we all recognise that the better. For too long we have chosen to hear 'rule of law' every time a Chinese official speaks of 'yifa zhiguo' or 'fazhi', and we think that they are aspiring to achieve our version of legal and political culture, but they just lack the capacity or techniques to get there. So we have focused on helping them build that capacity and meanwhile our paths are still not convergingor to the extent that they are converging, it might be because we are actually moving closer to them, rather than the other way around. The best thing 'yifa zhiguo' really has going for it is the promise of stability and order. I do not see any hint of democratic innovation out of such a paternalistic system that puts limits on basic freedoms of expression and association precisely to stunt the development of a democratic (as opposed to populist) culture. As for accountability, I think that, so long as the system relies on self-regulation and sees the regime itself as the ultimate source of moral authority, there will not be much innovation there either. I would not say that either democracy or accountability is faring much better in Western countries right now, but I do not see any reason to hold out hope that China's current path is leading to something superior.

ES: I do not agree that the rule of law should be thought of as a march. Political reform in China is controversial and no single idea leads inexorably towards liberalisation. If anyone is likely to think of the rule of law as a march towards a distant goal, it is the CCP. The Party's official doctrine embraces the Marxist theory of a historical materialism. Put simply, historical materialists believe social and political progress is achieved through historical and economic development. From this point of view, political ideas like the rule of law can be seen as waypoints on a longer march towards an inevitable, historical objective. It may also be politically convenient to think of the rule of law as something to be achieved gradually, in increments, alongside other economic objectives. Progress towards the rule of law is not the same as rule of law, and the more we think about where China is going, the less we think about where China actually is. This is not to say that the rule of law does not play an important role in Chinese politics. 85 million party members spent the latter part of 2014 talking about a version of the rule of law because it was the topic of the Fourth Plenum and, in areas where there is limited political opposition, China has made rapid progress. The current reforms to the justice sector will make life more predictable for millions of people. Both of these examples suggest ways in which the 'rule of law' agenda might promote a more accountable system of government in China. At the same time, we ought to resist the temptation to overstate its importance. It is official state policy to promote 'yifa zhiguo', but there is nothing fundamental about this. The policy yields to Cardinal Principles like Party Leadership.

ST: A number of basic elements of $\mathrm{Xi}$ Jinping's 'yifa zhiguo' push may, in the future, become very helpful in improving greater transparency and accountability. But the concept of 'yifa zhiguo' will not promote an overall improvement in the relationship between the Party-state and society (or more precisely between the Party and 'the people'). This is because the very purpose of 'yifa zhiguo' is to promote the idea that the law is a manifestation of the people's will and interests, and that the Party exists in order to protect the people's interests. Under the 'yifa zhiguo' ideology, the people cannot enjoy any rights and interests outside the leadership of the Party whose role it is to develop and protect (Party-initiated) rights and interests. 